\title{
Lise Öğrencilerinin Dil Öğrenme İnançları ve Öğrenen Özerkliğinin Akademik Başarı Açısından İncelenmesi
}

\author{
DOI: $10.26466 /$ opus. 356878 \\ * \\ Mustafa Durmusccelebi $^{*}$ - Hasan Bozgeyikli** ${ }^{*}$ Merve Çetinkaya $^{* * *}$ \\ * Doç. Dr., Erciyes Üniversitesi, Eğitim Fakültesi, Melikgazi / Kayseri / Türkiye

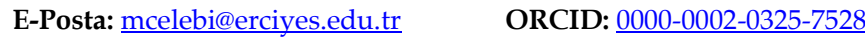 \\ ${ }^{*}$ Doç. Dr., Erciyes Üniversitesi, Eğitim Fakültesi, Melikgazi / Kayseri / Türkiye \\ E-Posta: hbozgeyikli@erciyes.edu.tr ORCID: 0000-0002-6762-1990 \\ *Yüksek Lisans Öğr., Erciyes Üniversitesi, Eğitim Bilimleri Enstitüsü / Kayseri / Türkiye

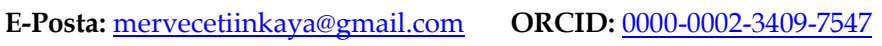

Öz

Son zamanlarda yapılan çalışmalar doğrultusunda öğrenen özerkliğinin aktif öğrenmenin ön koşullarından biri olduğu görülmektedir. Öğrenen özerkliği ile akademik başarı arasındaki ilişki bu sebeple önem taşımaktadır. Bu araştırmanın temel amacl; dil öğrenme inançları ve öğrenen özerkliği faktörlerinin dil öğrenme sürecinde akademik başarıya olan etkisini incelemektir. Tarama modeli ile yapılan bu araştırmanın evrenini Kayseri il merkezinde bulunan ortaöğretim öğrencileri oluşturmaktadır. Araştırmanın örneklemini ise basit tesadüfi yöntemle seçilen 223 öğrencidir. Araştırmada veri toplama aracı olarak "Öğrenen Özerkliği Ölçeği" ve "Dil Öğrenimi Hakkındaki Inançları Belirleme Envanteri" kullanılmıştır. Veriler analiz edildiğinde kadın öğrencilerin dil öğrenme inançlarının erkek öğrencilere oranla daha yüksek olduğu sonucuna ulaşılmıştır. Sinıf düzeyleri açısından incelendiğinde ise 9. sını öğrencilerinin dil öğrenme inançlarının daha yüksek olduğu sonucu ortaya çıkmıştır. Ayrıca kadın öğrencilerin öğrenen özerkliğinin erkek öğrencilerden daha yüksek olduğu sonucuna ulaşılmıştır. Akademik başarı bağlamında ise kadın öğrencilerin erkek öğrencilerden daha başarılı olduğu sonucuna ulaşılmıştır.

Anahtar Kelimeler: Öğrenme İnançları, Özerklik, Özerk Öğrenme 


\title{
Analysis of High School Students' Language Learn- ing Beliefs and Learning Autonomy in Terms of Ac- ademic Achievement
}

\begin{abstract}
In the recent studies show that learning autonomy is one of the prerequisities for active learning. The relationship between learning autonomy and academic achievement is important for this reason. The main purpose of this research is to examine the effects of language learning beliefs and learning autonomy factors on academic achievement in the language learning process. The population of this research is the highschool students of Kayseri. The sample group is a total 223 students selected by simple random method. "Autonomy Learner Questionnaire" and "Beliefs about Language Learning Inventory" were used as the data collection tools for this research. When the data are analyzed, it is concluded that female students have higher beliefs of language learning than male students. When examined from the perspective of class levels, it is concluded that 9th grade students have higher beliefs of language learning. It is also the result of the fact that the level of the learning autonomy of female students is higher than the level of the learning autonomy of male students. In the context of academic achievement, it is concluded that female learners are more successful than male learners.
\end{abstract}

Keywords: Autonomy, Autonomous Learning, Learning Beliefs

OPUS (c) Uluslararası Toplum Araştırmaları Dergisi-International Journal of Society Researches ISSN:2528-9527 E-ISSN : 2528-9535

http://opusjournal.net 


\section{Giriş}

Dil insan ilişkilerinde önemli bir yere sahip olan bir unsurdur. Dil, bireyin dünyadaki yerini ve değerini belirleyen olgudur. Konuşma yeteneği, yani dil, insanın en önemli özelliklerinin başında gelmektedir. İnsanın duygu, düşünce ve isteklerini açığa vurmasını, yaşamını devam ettirmesini sağlamaktadır. Dil, insanların toplum içerisinde yaşaması, bireyler ve toplumlar arası iletişimin sağlanması için gereklidir (Dağabakan ve Dağabakan, 2007).

Sunel'a (1989) göre yirminci yüzyılın ikinci yarısından sonra iletişim araçlarının gelişmesi, uluslar arasındaki siyasi, ekonomik ve turizm alanlarında alışverişin artması sayesinde yabancı dilin gerekliliği daha belirgin bir hale gelmiş ve yabancı dil öğrenimine olan istek artmıştır. Dil öğrenme süreci okuma, anlama, dinleme, konuşma gibi birçok önemli becerinin bir araya gelmesi ile oluşan bir süreçtir. Bu süreçte bireylerin dil öğrenimini kolaylaştıracak etmenler bulunmaktadır. Bunun yanı sıra belirli bir dil öğrenmeye farklı şekillerde yaklaşmaya neden olan ve öğrencilerde olan bireysel farklılıkların incelenmesinin büyük önem taşıdı̆̆ı dile getirilmektedir (Mori, 1999). Öğrencilerin sahip oldukları bireysel özellikler dil öğrenimindeki başarıyı etkilemektedir. Bu bireysel özelliklerin içinde öğrencilerin dil öğrenmeye karşı olan inançları, tutumları ve beklentileri bulunmaktadır (Aydın ve Zengin, 2008). Öğrencilerin yabancı dil öğrenme inançlarının ve yabancı dil öğrenmeye karşı olan tutumlarının hedef dilde bir yeterlilik seviyesine ulaşmadaki başarılarını etkilediği yapılan pek çok araştırmanın sonucu olarak ortaya çıkmıştır (Horwitz, 1988; Jernigan, 2001; Miele, 1982; Strevens, 1978). Mantle-Bromley (1995) öğrencilerin dil öğrenme ile ilgili inançlarının olumlu olmasının öğrenme ortamında öğrenci ve öğretmen arasındaki ilişkinin güven temelli olmasına ve bu ortamın da dil öğrenimini hızlandırdığını, öğrencilerin dil öğrenmeye karşı olumsuz inançlarının ise başarıyı engellediğini belirtmektedir.

Yabancı dil öğrenme sürecini etkileyen bir diğer önemli unsur ise öğrenen özerkliğidir. Benson'e (2001) göre özerklik “Bireyin kendi öğrenmesindeki sorumluluğu alma kapasitesi"dir. Candy (1991) özerk öğrenen bireylerin düzenli, disiplinli, mantıklı, analitik, kararlı, sorumluluk sahibi, atılgan, yaratıcı, bağımsız, öğrenme süreci hakkında bilgi sahibi, 
bilgiye ulaşma becerilerini geliştirebilen bireyler olması gerektiğini vurgulamiştır.

Wenden'e (1991) göre ise, özerk öğrenenlerin iki temel özelliği bulunmaktadır. Bunlar, öğrenenin kendi öğrenmesindeki sorumluğu almaya istekli olması ve bireyin kendine güvenmesidir. Dil öğrenme inançları ve öğrenen özerkliği dil öğrenimin etkileyen önemli faktörlerden olup yapılan birçok araştırmanın konusu olmuştur.

$\mathrm{Bu}$ çalışma dil öğrenme sürecini etkileyen dil öğrenme inançları ve öğrenen özerkliğini akademik başarı açısından incelemeyi amaçlamaktadır. Dil öğrenme inançlarının ve öğrenen özerkliğinin cinsiyet ve sınıf düzeyi açısından farklılık gösterip göstermediğini belirlemek amacıyla alt problemler oluşturulmuştur. Bu amaç doğrultusunda araştırmada aşağıdaki sorulara cevap aranmıştır:

1. Öğrencilerin dil öğrenme inançlarl;

a. Cinsiyete,

b. Sınıf düzeyine göre farklılık göstermekte midir?

2. Öğrencilerin öğrenen özerklikleri;

a. Cinsiyete ve

b. Sınıf düzeyine göre farklılık göstermekte midir?

3. Öğrencilerin akademik başarıları;

a. Cinsiyete ve

b. Sınıf düzeyine göre farklılık göstermekte midir?

4. Öğrencilerin dil öğrenme inançları, öğrenen özerklikleri ve akademik başarıları arasında anlamlı bir ilişki var mıdır?

5. Dil öğrenme inançları ve öğrenen özerklikleri akademik başarıyı anlamlı bir şekilde açıklamakta mıdır?

\section{Yöntem}

\section{Araștırmanın Modeli}

Lise öğrencilerinin dil öğrenme inançları ve öğrenen özerkliğinin akademik başarıları arasındaki ilişkiyi bulmayı amaçlayan bu araştırma, betimsel yöntemle yapılan tarama modelinde bir alan araştırmadır. Tarama modelleri, geçmişte ya da hala devam eden bir durumu var olan şekilde betimlemeyi amaçlayan araştırma yaklaşımlarıdır. Tarama mo- 
dellerinde araştırma konusu olan birey, olay veya nesne içinde bulunduğu koşullar içerisinde olduğu gibi tanımlanır ve herhangi bir şekilde onları değiştirme, etkileme çabası gösterilmez. Bilinmek istenen şey vardır ve oradadır. Önemli olan ona uygun bir şekilde gözleyip belirleyebilmektir (Karasar, 2011). Anketle toplanan verilerin çözümünde, ilişkisel tarama yöntemi kullanılmıştır.

\section{Katılımcilar}

Araştırmanın evreni 2016-2017 Eğitim-Öğretim yılı içerisinde bulunan Kayseri İl Milli Eğitim Müdürlüğüne bağlı devlet okullarındaki ortaöğretim öğrencileridir. Çalışma evreni ise Kayseri ilindeki okullardan tesadüfi yöntemle seçilen ortaöğretim öğrencilerinden oluşmaktadır. Çalışma evreni için devlet okullarından olan 1 Sosyal Bilimler Lisesi ve 1 Anadolu Lisesinde çalışılmıştır. Bu okullardan örneklemi sağlayacak 119 Anadolu Lisesi ve 104 Sosyal Bilimler Lisesi öğrencisi olarak toplam 223 ortaöğretim öğrencisi seçilmiştir.

Katılımcıların okul türü, sınıf düzeyi, cinsiyet değişkenlerine göre dağllımları Tablo 1'de verilmiştir.

Tablo 1. Katılımcıların cinsiyet, öğrenim gördükleri okul türü ve sınıf düzeylerine göre dă̆ılımı

\begin{tabular}{llll}
\hline & & $N$ & $\%$ \\
\hline \multirow{2}{*}{ Cinsiyet } & Kadın & 128 & 57,39 \\
& Erkek & 95 & 42,61 \\
Okul Türü & Sosyal Bilimler & 104 & 46,63 \\
& Anadolu Lisesi & 119 & 53,36 \\
& 9. Sinıf & 57 & 25,56 \\
Sinıf Düzeyi & 10. Sinıf & 56 & 25,12 \\
& 11. Sinıf & 73 & 32,73 \\
Toplam & 12. Sinıf & 37 & 16,59 \\
\hline
\end{tabular}




\section{Veri Toplama Araçları}

$\mathrm{Bu}$ araştırmada veri toplama aracı olarak katılımcıların öğrenen özerkliğini belirlemek için Egel (2003) tarafından geliştirilen ve 44 maddeden oluşan "Öğrenen Özerkliği Ölçeği” kullanılmıştır. Ölçekte 9 alt boyut bulunmaktadır; özyönelim hazırlığı (6 madde), dil öğrenmede bağımsız çalışma (7 madde), öğretmenin önemi (8 madde), öğretmenin rolü (5 madde), dil öğrenme etkinlikleri (4 madde), içerik seçimi (3 madde), amaç ve değerlendirme ( 2 madde), değerlendirme ve motivasyon (5 madde), diğer kültürler (4 madde) olarak adlandırılmıştır. Ölçeğin yapılan güvenirlik çalışmasında Cronbach Alpha değeri 0,81 olarak bulunmuştur. Ölçeğin derecelendirilmesi "hiçbir zaman doğru değil - çok bağımlı/özerk (1) ... her zaman doğru - çok bağımsız/özerk (5)" şeklinde yapılmıştir.

Araştırmada katılımcıların yabancı dil öğrenmeye karşı inançlarını belirlemek için Horwitz (1988) tarafından geliştirilen ve 34 maddeden oluşan "Dil Öğrenimi Hakkındaki İnançları Belirleme Envanteri (Beliefs About Language Learning Inventory)" araştırmacı tarafından uzman görüşleri alınmış ve Türkçeye uyarlanarak kullanılmıştır. Ölçeğin güvenirliğini belirlemek için yapılan Cronbach Alpha değeri 0,78 olarak bulunmuştur.

\section{Verilerin Analizi}

Verilerin analiz edilmesinde; betimsel analizler için yüzde, frekans ve aritmetik ortalama gibi tekniklerden yararlanılmıştır. Öğrencilerin dil öğrenme inançları, öğrenen özerklikleri ve akademik başarılarının cinsiyet ve sınıf düzeylerine göre farklılıklarını belirlemek amacıyla cinsiyet değişkeni için t-testi, sınıf düzeyi için anova teslinden yararlanılmıştır. Öğrencilerin dil öğrenme inançları, öğrenen özerklikleri ve akademik başarıları arasındaki ilişki düzeyini belirlemek için pearson korelasyon katsayısı kullanılmıştır. Dil öğrenme inançları ve öğrenen özerkliğinin akademik başarıyı ne düzeyde açıkladığını ortaya koyabilmek için regresyon tekniği kullanılarak analiz yapılmıştır. 


\section{Bulgular}

Bu bölümde araştırmanin alt problemleri çerçevesinde elde edilen bulgulara yer verilmiştir. Tablo 2'de öğrencilerin dil öğrenme inançları, öğrenen özerkliği ve akademik başarılarının cinsiyetlerine göre farklılıklarını belirten veriler yer almaktadır.

Tablo 2. Öğrencilerin dil öğrenme inançları, öğrenen özerkliği ve akademik başarılarinın cinsiyetlerine göre farkliliklar

\begin{tabular}{llllllll}
\hline & Cinsiyet & \multicolumn{1}{c}{$\mathbf{N}$} & $\mathbf{\mathbf { X }}$ & \multicolumn{1}{c}{$\mathbf{S}$} & $\mathbf{s d}$ & $\mathbf{t}$ & $\mathbf{p}$ \\
\hline Dil Öğrenme & Kadın & 128 & 22,87 & 3,82 & \multirow{2}{*}{221} & \multirow{2}{*}{2,27} & \multirow{2}{*}{002} \\
İnançları & Erkek & 95 & 21,75 & 3,29 & & & \\
Öğrenen & Kadın & 128 & 15,94 & 2,40 & \multirow{2}{*}{221} & \multirow{2}{*}{3,081} & \multirow{2}{*}{024} \\
Özerkliği & Erkek & 95 & 14,98 & 2,14 & & & \\
Akademik & Kadın & 123 & 4,15 & 1,04 & \multirow{2}{*}{210} & 2,73 & \multirow{2}{*}{007} \\
Başarı & Erkek & 89 & 3,75 & 1,06 & & & \\
\hline
\end{tabular}

$\mathrm{p}<, 05$

Tablo 2'de görüldüğü gibi, öğrencilerin dil öğrenme inançları, öğrenen özerklikleri ve akademik başarıları cinsiyet değişkenine göre farklılaşmaktadır. Tablodaki aritmetik ortalamalar incelendiğinde, her üç değişken açısından da kadın öğrencilerin erkek öğrencilere göre daha yüksek ortalamaya sahip olduğu görülmektedir.

Tablo 2'de görüldüğü üzere, dil öğrenme inançları cinsiyet açısından anlamlı düzeyde farklılık göstermektedir. Ortalamalara bakıldığında kadın öğrencilerin dil öğrenme inançları erkek öğrencilerden daha yüksektir.

Tablo 3'te öğrencilerin dil öğrenme inançları sınıf düzeyine değiş̧keni açısından incelenmektedir.

Tablo 3. Dil öğrenme inançlarııı sınf düzeyine göre incelenmesi

\begin{tabular}{lllllllll}
\hline & $\boldsymbol{N}$ & $\overline{\boldsymbol{X}}$ & SS & Sh. & $\boldsymbol{F}$ & $\boldsymbol{p}$ & Tukey & Sig. \\
\hline 9. Sinif & 57 & 23,66 & 2,74 &, 36 & & & 11. Sinif &, 042 \\
10. Sinif & 56 & 21,95 & 3,96 &, 52 & & & & \\
11. Sinif & 73 & 21,98 & 3,86 &, 45 & 3,197 &, 000 & 9. Sinif &, 042 \\
12. Sinif & 37 & 21,93 & 3,56 &, 58 & & & & \\
Toplam & 223 & 22,39 & 3,64 &, 24 & & & & \\
\hline
\end{tabular}


Tablo 3 incelendiğinde, dil öğrenme inançları sınıf düzeyine göre anlamlı bir fark göstermektedir. Farkın nerden kaynaklandığını belirlemek amacı ile yapılan Post Hoc testinde, dokuzuncu sınıf öğrencileri ile on birinci sınıf öğrencilerinin dil öğrenme inançları arasında fark ortaya çıkmaktadır. 9. sınıf öğrencilerinin dil öğrenme inançları diğer sınıf düzeylerindeki öğrencilerin dil öğrenme inançlarından daha yüksektir.

Araştırmanın ikinci alt problemi öğrenen özerkliğinin cinsiyet ve sınıf düzeyi değişkenine göre farklılık gösterip göstermediğini belirlemeye yöneliktir. Tablo 4'te öğrencilerin öğrenen özerkliklerinin cinsiyet açısından incelenmesi yer almaktadır.

Tablo 4. Öğrenen özerkliğinin cinsiyete göre incelenmesi

\begin{tabular}{llllllll}
\hline & Cinsiyet & $\mathrm{N}$ & $\overline{\mathrm{X}}$ & $\mathrm{S}$ & $\mathrm{sd}$ & $\mathrm{t}$ & $\mathrm{p}$ \\
\hline Öğrenen & Kadın & 128 & 15,94 & 2,40 & \multirow{2}{*}{221} & \multirow{2}{*}{3,081} & \multirow{2}{*}{024} \\
Özerkliği & Erkek & 95 & 14,98 & 2,14 & & & \multirow{2}{*}{} \\
\hline
\end{tabular}

Tablo 4'e göre, öğrenen özerkliği cinsiyet değişkenine göre anlamlı düzeyde değişmektedir. Ortalamalara bakıldığında kadın öğrencilerin öğrenen özerklik düzeyi erkek öğrencilere oranla daha yüksektir.

Tablo 5'te öğrencilerinin öğrenen özerkliklerinin sınıf düzeyi açısından incelenmesi yer almaktadır.

Tablo 5. Öğrenen özerkliğinin sınf düzeyine göre incelenmesi

\begin{tabular}{llllll}
\hline & $N$ & $\bar{X}$ & SS & Sh. & F \\
\hline 9. Sinıf & 57 & 15,57 & 2,05 &, 27 & \\
10. Sinıf & 56 & 15,77 & 2,43 &, 32 & \\
11. Sinıf & 73 & 15,56 & 2,49 &, 29 &, 764 \\
12. Sinif & 37 & 15,03 & 2,31 &, 38 & \\
Toplam & 223 & 15,53 & 2,33 &, 15 & \\
\hline
\end{tabular}

Tablo 5 'te görüldüğü üzere öğrenen özerkliği sınıf düzeyi değişkenine göre anlamlı bir farklılık göstermemektedir.

Araştırmanın üçüncü alt problemi akademik başarının öğrencilerin cinsiyete ve sınıf düzeyine göre farklılık gösterip göstermediğini tespit etmektir. Tablo $6^{\prime}$ da öğrencilerin akademik başarılarının cinsiyet açısından incelenmesi yer almaktadır. 
Lise Öğrencilerinin Dil Öğrenme İnançları ve Öğrenen Özerkliğinin Akademik Başarı Açısından İncelenmesi

Tablo 6. Akademik başarının cinsiyete göre incelenmesi

\begin{tabular}{llllllll}
\hline & Cinsiyet & $\mathbf{N}$ & $\overline{\mathbf{X}}$ & $\mathbf{S}$ & $\mathbf{s d}$ & $\mathbf{t}$ & $\mathbf{p}$ \\
\hline Akademik & Kadın & 123 & 4,15 & 1,04 & \multirow{2}{*}{210} & \multirow{2}{*}{2,73} & \multirow{2}{*}{007} \\
Başarı & Erkek & 89 & 3,75 & 1,06 & & & \\
\hline
\end{tabular}

Tablo 6'da, akademik başarının cinsiyete göre anlamlı düzeyde bir fark gösterdiği görülmektedir. Ortalamalara bakıldığında kadın öğrencilerin akademik başarı düzeyleri erkek öğrencilerden daha yüksek olduğu görülmektedir.

Tablo 7'de öğrencilerin akademik başarılarının sınıf düzeyi açısından incelenmesi yer almaktadır.

Tablo 7. Akademik başarının sınıf düzeyine göre incelenmesi

\begin{tabular}{llllll}
\hline & $\mathbf{N}$ & $\overline{\boldsymbol{X}}$ & SS & Sh. & F \\
\hline 9. Sinıf & 57 & 3,70 & 1,28 &, 17 & \\
10. Sinif & 56 & 4,07 &, 97 &, 13 & \\
11. Sinif & 73 & 4,16 &, 98 &, 11 & 1,99 \\
12. Sinif & 37 & 3,94 &, 95 &, 16 & \\
Toplam & 223 & 3,98 & 1,07 &, 07 & \\
\hline
\end{tabular}

Tablo 7'de görüldügü üzere, akademik başarı sınıf düzeyine göre anlamlı bir farklılık göstermemektedir.

Araştırmanın dördüncü alt problemi öğrencilerin dil öğrenme inançları, öğrenen özerklikleri ve akademik başarıları arasında anlamlı bir ilişki olup olmadığını belirlemeye yöneliktir.

Tablo 8'de öğrencilerin dil öğrenme inançları ve akademik başarıları arasındaki ilişki incelenmektedir.

Tablo 8. Dil öğrenme inançlan ve akademik başarn arasındaki ilişkinin incelenmesi

\begin{tabular}{llllll}
\hline Değişken & $\mathbf{N}$ & $\overline{\mathbf{X}}$ & $\mathbf{S S}$ & $\mathbf{p}$ & $\mathbf{r}$ \\
\hline Dil Öğrenme İnançları & 223 & 22,39 & 3,64 & \multirow{2}{*}{1} & \multirow{2}{*}{, 755} \\
Akademik Başarı & 212 & 3,98 & 1,07 & & \\
\hline
\end{tabular}

Tabloda görüldüğü üzere dil öğrenme inançları ile akademik başarı arasında anlamlı düzeyde pozitif $(\mathrm{r}=, 755)$ bir ilişki bulunmaktadır. 
Tablo 9'da öğrencilerin öğrenen özerklikleri ve akademik başarıları arasındaki ilişki incelenmektedir.

Tablo 9. Öğrenen özerkliği ve akademik başarı arasındaki ilişkinin incelenmesi

\begin{tabular}{llllll}
\hline Değişken & $\mathbf{N}$ & $\overline{\mathbf{X}}$ & $\mathbf{S S}$ & $\mathbf{p}$ & $\mathbf{r}$ \\
\hline Öğrenen Özerkliği & 223 & 15,53 & 2,33 & \multirow{2}{*}{001} & \multirow{2}{*}{235} \\
Akademik Başarı & 212 & 3,98 & 1,07 & & \\
\hline
\end{tabular}

Tablo 9'da öğrenen özerkliği ile akademik başarı arasında pozitif (r= ,235) yönde düşük düzeyde ilişki bulunduğu görülmektedir.

Araştırmanın son alt problemi dil öğrenme inançları ve öğrenen özerkliklerinin akademik başarı üzerindeki etkisini belirlemeye yöneliktir. Tablo 10 'da dil öğrenme inançları ve öğrenen özerkliklerinin akdemik başarı üzerindeki etkisi incelenmektedir.

Tablo 10. Dil öğrenme inançları ve öğrenen özerkliğinin akademik başarı üzerindeki etkisi

\begin{tabular}{lllclc}
\hline Model & Değişken & R & $\boldsymbol{R}^{\mathbf{2}}$ & $\mathbf{F}$ & Sig. \\
\hline 1 & Akademik Başarı &, $\mathbf{2 3 9}^{\boldsymbol{a}}$ &, 057 & 6,35 & $\mathbf{0 0 2}^{\boldsymbol{b}}$ \\
\hline
\end{tabular}

Dil öğrenme inançları ve öğrenen özerkliğinin akademik başarı üzerindeki etkisini tespit etmek amacı ile yapılan regresyon analizinde dil öğrenme inançları ve öğrenen özerkliğinin akademik başarıyı \%6 oranında açıkladığı görülmektedir.

\section{Sonuç, Tartışma ve Öneriler}

Lise öğrencilerin dil öğrenme inançları ve öğrenen özerkliklerinin akademik başarı açısından incelenmesini amaçlayan bu çalışmada, ulaşılan sonuçlar ve alanda yapılan çalışmalar ile karşılaştırmalar, araştırmanın alt problemleri çerçevesinde aşağıda verilmektedir.

Bu çalışmada dil öğrenme inançlarının cinsiyet açısından anlamlı bir farklılık gösterdiği sonucuna ulaşılmıştır. Kadın öğrencilerin dil öğrenme inançları erkek öğrencilere oranla daha yüksektir. Dil öğrenme inançları sınıf düzeyi değişkenine göre incelendiğinde ise, dokuzuncu sınıf öğrencilerinin dil öğrenme inançlarının daha yüksek olduğunu sonucuna ulaşılmıştır. Bu çalışmanın sonuçlarına benzer olarak, Rieger'un (2009) İngilizce ve Almanca bölümlerinde öğrenim gören Macar öğren- 
ciler ile yaptığı bir çalışmada öğrencilerin cinsiyetleri ile yabancı dil öğrenme inançları arasında anlamlı bir farklılık tespit edilmiştir. Kadın öğrencilerin erkek öğrencilerden daha yüksek düzeyde dil öğrenme inançlarına sahip olduğu sonucuna ulaşılmıştır.

Yapılan başka bir çalışmada ise bu çalışmanın sonuçlarından farklı sonuçlar bulunmuştur. Er (2011) tarafından, zorunlu yabancı dili Almanca, Fransızca ve İngilizce olan öğrencilerin katılımı ile yapılan bir çalışmada, Almanca, Fransızca ve İngilizce grubunda dokuzuncu sınıf öğrencilerinin onuncu, on birinci ve on ikinci sınıf öğrencilerine oranla yabancı dil öğrenme inançlarının yüksek düzeyde olduğu sonucuna ulaşılmıştır. Aynı çalışmada öğrencilerin cinsiyetlerine göre yabancı dil öğrenme inançları arasında anlamlı bir fark olmadığı ortaya çıkmıştır. Ayrıca aynı araştırmada katılımcıların yabancı dil puanları, dil öğrenme kaygısı ve yabancı dil öğrenme inançları arasında anlamlı pozitif bir ilişki olduğu görülmüştür.

Çalışmaların sonuçlarının farklılık göstermesi farklı okullarda öğrenim gören öğrencilerin yaşadığı çevreden, ekonomik ve sosyal hayatlarının farklı oluşundan kaynaklanabilir. Öğrencilerin dil öğrenme inançlarının sınıf düzeyi değiştikçe değişmesi yabancı dil öğretmenlerinin tutumlarından kaynaklanabilir. Öğrencilerin dil öğrenme inançlarının yüksek tutulması için öğretmenlerin öğrencilere uyguladıkları yöntemlerin değiştirilmesi ile sağlanabilir. Bu yöntemlerin farklılaşması için ise öğretmenlerin kendilerini geliştirmeleri, yeniliklere ve farklı stratejilere açık olmaları gerekmektedir.

Çalışmada, öğrenen özerkliği cinsiyet değişkenine göre anlamlı düzeyde farklılık gösterip, kadın öğrencilerin öğrenen özerkliğinin erkek öğrencilerden daha yüksek olduğu bulgusuna ulaşılmıştır. Öğrenen özerkliği sınıf düzeyine göre ise anlamlı düzeyde bir farklılık göstermemektedir. Bir başka çalışmada ise üniversite öğrencileri ile yapılan ve öğrencilerin özerk öğrenmede sorumluluk alıp almadıklarını inceleyen bir araştırmada, kadın öğrencilerin özerk öğrenmede kendilerini erkek öğrencilerden daha aktif buldukları sonucuna ulaşılmış ancak sorumluluk alma düzeyinin cinsiyete göre anlamlı bir fark göstermediği görülmüştür (Üstünlüoğlu, 2009).

Erbil Tursun'un (2010) yaptığ1 öğrencilerin ve öğretmenlerin öğrenen özerkliğinin incelendiği bir çalışmada ise, öğrencilerin İngilizce dersi ile 
ilgili sorumlulukları öğretmenleri ile paylaşmaya hazır oldukları ancak öğretmenlerin dersin sorumluluklarını öğrenciler ile paylaşmaya hazır olmadıkları görülmüştür. Aynı çalışmada erkek öğrencilerin kadın öğrencilere göre sorumluluk üstlenmede daha istekli oldukları sonucuna ulaşılmıştır.

Bu çalışma ve yapılan diğer çalışmalarda öğrencilerin öğrenim düzeyinin lise veya üniversite olması sonuçlar açısından farklılık göstermiş olabilir. Öğrencilerin yabancı dil öğreniminde artan sorumlulukları özerk öğrenmeye olumlu bir katkı sağlamış olabilir. Ancak öğrencilerin özerk öğrenmesine öğretmenlerin özerkliği destekleyici davranışlar göstermesi gerekmektedir. Bu sebeple öğretmenler sınıf içinde tüm sorumluluğu kendileri almamaları, öğrenim süreci içerisinde öğrencilere daha fazla yer vermeli ve onların kendi öğrenme sorumluluklarını almalarını sağlamalıdır.

Akademik başarı cinsiyete göre incelendiğinde kadın öğrencilerin erkek öğrencilerden daha yüksek akademik başarıya sahip olduğu ortaya çıkmış ve sınıf düzeyine göre akademik başarı anlamlı düzeyde bir farklılık göstermemiştir.

Vatanartıran, Dalgıç ve Karadeniz (2014) tarafından öğrencilerin yabancı dil başarısını açıklayan etmenleri belirlemek amacıyla yapılan bir çalışmada kız öğrencilerin yabancı dil başarı puanlarının erkek öğrencilerden daha yüksek olduğu sonucuna ulaşılmıştır.

Aydın (2006) tarafından yapılan bir çalışmada da kız öğrencilerin erkek öğrencilere oranla ilinci dil olarak İngilizce öğreniminde daha başarılı oldukları gözlemlenmiştir. Bu çalışmaya paralel olarak cinsiyetler arasındaki bu farkın kız öğrencilerin yabancı dil öğrenimine karşı tutumlarının daha olumlu olmasından kaynaklandığı söylenebilir (Kubota, 2003).

Öğrencilerin dil öğrenme inançları ile akademik başarıları arasında anlamlı bir ilişki bulunan bu çalışmada öğrenen özerkliği ile akademik başarı arasında da anlamlı bir ilişki bulunduğu sonucuna ulaşılmıştır. Bayat (2007), İngilizce öğrenen üniversite öğrencilerinin özerklik algısı düzeylerinin okuduğunu anlama başarı düzeylerini ve sınıf içi davranış düzeylerini belirlemek için yaptığ çalışmada katılımcıların özerklik algılarının yüksek olduğu ve özerklik algısı ile okuduğunu anlama başarısı arasında anlamlı bir ilişki olduğu sonucuna ulaşmıştır. 
Büyükyazı (2010) tarafından yapılan hazırlık öğrencilerinin ve öğretmenlerinin İngilizce öğrenme hakkındaki inançlarını belirlemek amacıyla yapılan bir çalışmada bulgular öğrencilerin dil öğrenme sürecine onların başarısına etki edecek bazı kesin inançlar ile girmiş olduğunu göstermektedir.

Çalışmalardan çıan sonuçlar göz önüne alındığında dil öğrenme sürecini etkileyen iki önemli faktör olan dil öğrenme inançları ve öğrenen özerkliği öğretmenler tarafından dikkate alınmalıdır. Bu çalışmada dil öğrenme inançları ve öğrenen özerkliğinin öğrencilerin akademik başarılarını \%6 oranında açıkladığı sonucuna ulaşılmıştır.Bu çalışmadan çıkan sonuçlarda görüldüğü üzere öğrencilerin yabancı dil öğreniminde dil öğrenme inançlarının ve öğrenmedeki özerkliklerinin akademik başarıya etkisi bulunmaktadır. Öğretmenlerin öğrencilerin dil öğrenme inançlarının farkında olmalı ve sınıf içinde yöntem ve ders planlamasına bu inançlara dikkat etmelidirler. Ayrıca dersin hedefleri ve sınıf düzeyleri değiştikçe bu inançların değişiklik gösterebileceği düşünülerek eğitim programları bu inançları geliştirebilecek şekilde hazırlanmalıdır. Sınıfta öğretmenler öğrenen özerkliğine önem vermeli, öğrencilerin kendi sorumluluklarını alabilecek şekilde onlara görevler vermeli ve öğrencileri kendine güvenen, sorumluluk almayı becerebilen bireyler olarak yetiştirmelidirler.

\section{Kaynakça}

Aydın, S. (2006). İkinci dil olarak ingilizce öğrenimindeki başarı düzeyinin bazı değişkenlere göre incelenmesi. Atatürk Üniversitesi Sosyal Bilimler Enstitüsü Dergisi, 8(2), 273-285.

Aydın, S., ve Zengin, B. (2008). Yabancı dil öğreniminde kayg1: Bir literatür özeti. Journal of Language and Linguistic Studies, 4(1), 81-94.

Bayat, Ö. (2007). Yabancı dil olarak ingilizce öğrenenlerde özerklik algısı, okuduğunu anlama başarısı ve sınıf içi davranışlar arasındaki ilişkiler. Yayımlanmamış Doktora Tezi, Dokuz Eylül Üniversitesi Eğitim Bilimleri Enstitüsü, İzmir.

Benson, P. (2001). Teaching and researching autonomy in language learning. Essex: Pearson Education. 
Büyükyazı, M. (2010). The beliefs of university foreign language students and their teachers about language learning. Sosyal Bilimler 8.1. 169-182.

Candy, P.C. (1991). Self-direction For Lifelong Learning. California: JosseBass

Dağabakan, F. Ö., ve Dağabakan, D. (2007). Dil ve çocukta dil gelişim kuramları. Millî Eğitim Dergisi, 174, 155-161.

Egel, İ.P. (2003). The impact of the European language portfolio on the learner autonomy of Turkish primary school students. Yayımlanmamış Doktora Tezi. Anadolu Üniversitesi, Eskişehir.

Er, S. S. (2011). Anadolu liselerine devam eden öğrencilerin yabancı dil başarılarında yabancı dile yönelik kayğ ve inançlarının etkisinin incelenmesi. Yayımlanmamış Doktora Tezi, Ankara Üniversitesi Fen Bilimleri Enstitüsü, Ankara.

Erbil Tursun, S. (2010). Ortaöğretim ingilizce dersinde öğrencilerin ve öğretmenlerin öğrenen özerkli ile ilgili görüşleri. Yayınlanmamış Yüksek Lisans Tezi. Trakya Üniversitesi, Edirne.

Horwitz, E.K. (1987). Surveying student beliefs about language learning. In A. L. Wenden, and J. Rubin (Eds.), Learner strategies in language learning (pp.119-129). Prentice-Hall. Englewood, Cliffs, NJ.

Horwitz, E.K. (1988). The beliefs about language learning of beginning university foreign language students. Modern Language Journal, $72,283-294$.

Jernigan, C. G. (2001). The role of bieliefs, attributions, and preceived goal attainment in students' motivation. In G. Brauer (Ed.), Pedagogy of language learning in higher education (pp. 23-45). Westport, CT: Ablex.

Kaçar, I. G., ve Zengin, B. (2009). İngilizceyi yabancı dil olarak öğrenenlerin dil öğrenme ile ilgili inançları, öğrenme yöntemleri, dil öğrenme amaçları ve öncelikleri arasındaki ilişki: Öğrenci Boyutu. Journal of Language and Linguistic Studies, 5 (1), 55-89.

Kubota, R. (2003). New approaches to gender, class, and race in second language writing. Journal of Second Language Writing, 12(1), 31-47.

Mantle-Bromley, C. (1995). Positive attitudes and realistic beliefs: Links to proficiency. Modern Language Journal, 77 (1), 11-22. 
Miele, P. (1982). Suggestopedia: Easier learning the natural way. Sandy Spring, MD: Utopia Unlimited.

Mori, Y. (1999). Epistemological beliefs and language learning beliefs: What do language learners believe about their learning? Language Learning. 49(3), 337-415.

Rieger, B. (2009). Hungarian university students' beliefs about language learning: A questionnaire study. Working Papers in Language Pedagogy, 3, 97-113.

Strevens, P. (1978). The nature of language teaching. In R. C. Richards (Ed.), Understanding second and foreign language learning: Issues and approaches (pp. 179-203). Rowley: Newbury House.

Sunel, A. H. (1989). Yabancı dil öğretiminde metot sorunu. Hacettepe Üniversitesi Ĕ̆itim Fakültesi Dergisi, 4(4), 137-143.

Üstünlüoğlu, E. (2009). Autonomy in language learning: Do students take responsibility for their learning? Journal of Theory and Practice in Education, 5(2), 148-169

Vatanartıran, S., Dalgı̧̧, G., ve Karadeniz, Ş. (2014). Factors related with students' foreign language achievement. Pegem Eğitim ve Öğretim Dergisi, 4(3), 01-18.

Wenden, A. (1991). Learner strategies for learner autonomy. New York, NY: Prentice Hall.

\section{Kaynakça Bilgisi / Citation Information}

Durmuşçelebi, M., Bozgeyikli, H ve Çetinkaya, M. (2018). Lise öğrencilerinin dil öğrenme inançları ve öğrenen özerkliğinin akademik başarı açısından incelenmesi. OPUS - Uluslararası Toplum Araştırmaları Dergisi, 8(Gençlik Araştırmaları Özel Sayısı), 248-262. 